University of Nebraska - Lincoln

DigitalCommons@University of Nebraska - Lincoln

Faculty Publications: Department of

Entomology

Entomology, Department of

2007

\title{
Utility of Morphological and Molecular Techniques for \\ Determination of Paternity in Two Subspecies of Diabrotica undecimpunctata (Coleoptera: Chrysomelidae)
}

\author{
Isaac 0. Oyediran \\ Monsanto Company, isaac.o.oyediran@monsanto.com \\ Thomas L. Clark \\ University of Nebraska-Lincoln \\ Steven R. Skoda \\ USDA-ARS, Steve.Skoda@ars.usda.gov \\ Elvis A. Heinrichs \\ University of Nebraska - Lincoln, eheinrichs2@unl.edu
}

Follow this and additional works at: https://digitalcommons.unl.edu/entomologyfacpub

Part of the Entomology Commons

Oyediran, Isaac O.; Clark, Thomas L.; Skoda, Steven R.; and Heinrichs, Elvis A., "Utility of Morphological and Molecular Techniques for Determination of Paternity in Two Subspecies of Diabrotica undecimpunctata (Coleoptera: Chrysomelidae)" (2007). Faculty Publications: Department of Entomology. 917.

https://digitalcommons.unl.edu/entomologyfacpub/917

This Article is brought to you for free and open access by the Entomology, Department of at DigitalCommons@University of Nebraska - Lincoln. It has been accepted for inclusion in Faculty Publications: Department of Entomology by an authorized administrator of DigitalCommons@University of Nebraska - Lincoln. 


\title{
Utility of Morphological and Molecular Techniques for Determination of Paternity in Two Subspecies of Diabrotica undecimpunctata (Coleoptera: Chrysomelidae) ${ }^{1}$
}

\author{
Isaac O. Oyediran, ${ }^{2}$ Thomas L. Clark, ${ }^{2}$ Steve R. Skoda, ${ }^{3}$ Elvis A. Heinrichs and \\ John E. Foster
}

Insect Genetics Laboratory, Department of Entomology, University of Nebraska, Lincoln, Nebraska 68583-0816 USA

\section{J. Entomol. Sci. 42(2): 174-184 (April 2007)}

\begin{abstract}
An experiment was conducted to determine the paternity of $F_{1}$ progeny using morphological and molecular methods in Diabrotica (Coleoptera: Chrysomelidae) subspecies: Diabrotica undecimpunctata howardi Barber, also known as spotted cucumber beetle, and $D$. undecimpunctata undecimpunctata Mannerheim, also known as western cucumber spotted beetle. Results from crosses that involved the females of $D$. $u$. howardi and the males of $D . u$. undecimpunctata had all $F_{1}$ progeny with phenotypes as the male parent. Similarly, in all the crosses that involved the females of D. u. undecimpunctata and the males of the D. u. howardi, all the $F_{1}$ progeny had phenotypes as the male parent. DNA from females and males were amplified using two primers to confirm the paternity of $F_{1}$ progeny. The study on the inheritance of body color in these two subspecies appeared to be governed by one dominant gene (monogenic), and it is the male that determines the body color of progeny in both subspecies.
\end{abstract}

Key Words Diabrotica subspecies, body color, marker, inheritance

Diabrotica undecimpunctata is taxonomically divided into a complex of at least 4 described subspecies (Smith and Lawrence 1967, Krysan 1986) with each being separated by geographical range and morphological characters (i.e., color). For example, coloration and patterns on the elytra of southern corn rootworm, $D$. $u$. subsp. howardi, and western spotted cucumber beetle, $D$. u. undecimpunctata, are the same whereas the former has a black abdomen and latter has a yellow abdomen. While such phenotypic observations are common for many insect species (and subspecies), they can have important utility if their modes of inheritance are known making it possible to study topics such as mating patterns, mating frequency, mate choice, and paternity. For example, Lu and Logan (1994) used body color as a marker to study color inheritance in Leptinotarsa decemlineata Say.

In addition to phenotypic characters, molecular techniques such as allozyme and DNA markers have proven valuable in genotypic studies of paternity determination; Huettel et al. (1976) studied paternity in plum curculio, Conotrechelus nenuphar Herbst (Coleoptera: Curculionidae), using allozyme markers. DNA methods, such as

\footnotetext{
${ }^{1}$ Received 30 June 2006; accepted for publication on 27 July 2006.

${ }^{2}$ Address inquiries (email:isaac.o.oyediran@monsanto.com). Current address: Monsanto Company, 700 Chesterfield Pkwy W, Chesterfield MO 63017.

${ }^{3}$ USDA-ARS-MLIRU, University of Nebraska, Lincoln, NE 68583-0938 USA.
} 
random amplified polymorphic DNA (RAPD) markers that consist of relatively short DNA fragments, also have proven useful in paternity inheritance studies (Huettel et al. 1976). An advantage of the RAPD technique is that it requires no foreknowledge or any specific gene in a target taxon, and it is random with respect to the genome (Hoy 1990). Hadrys et al. (1993) first demonstrated the usefulness of RAPD for analyzing paternity in the dragonfly, Anax parthenope Sélys (Odonata: Aeshnidae). Also, Achmann et al. (1992) and Hooper and Siva-Jothy (1996) used RAPD-PCR for determining paternity in bush cricket, Poecillimon veluchianus Fieber (Orthoptera: Tettigonidae).

In the current study, we used body color a morphological trait and molecular techniques to determine paternity in two subspecies of $D$. u. undecimpunctata. The mode of inheritance of the body color also was studied.

\section{Materials and Methods}

Insect cultures. Diabrotica $u$. howardi colony originated from beetles collected from the University of Nebraska-Lincoln, Agricultural Research Development Center farm near lthaca, NE (Saunders Co). The D. u. undecimpunctata colony was provided by Syngenta Corp. (formerly Zeneca Corp.) with beetles originating near Richmond, CA (Alameda Co). Beetles (both subspecies) were maintained in environmental growth chambers at $27^{\circ} \mathrm{C}$ and at a relative humidity between $30-60 \%$, in cages measuring $28 \times 28 \mathrm{~cm}$, at 16:8 [L:D]. Standard Diabrotica rearing techniques were used throughout the study (Cuthbert et al.1968, Branson et al. 1988, Tallamy and Pesek 1996); larvae were reared on seedlings of maize and beetles on lettuce, Lactuca sativa L., and fresh sweet maize ears. To reduce disease incidence, insect cages were washed every other day with detergent and a $1 \%$ sodium hypochlorite solution.

Insect crosses. Five crosses, of each of the following categories were done:

(1) WSCB $+\times$ WSCB ${ }^{\star}$; (2) WSCB $\mathrm{WS}^{\circ} \times \mathrm{SCB}^{\star}$;

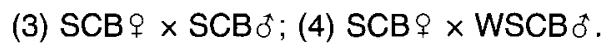

Each male and each female were placed in a small plastic oviposition box (Gray Plastic Packing Co, Bronx, NY), a modification of the Boetel and Fuller (1997) technique, at 16:8 [L:D] photoperiod and $27^{\circ} \mathrm{C}$ with moistened silt loam soil that had been sieved through a \#60 mesh sieve and autoclaved at $250^{\circ} \mathrm{C}$ for $30 \mathrm{~min}$. The soil was moistened to near saturation and scarified to serve as an oviposition substrate. After oviposition, eggs were removed from the soil once a week by washing (in water at room temperature) the mixture into a 60-mesh sieve and then washing onto moistened filter paper that was then placed in a Petri dish $(14 \times 2 \mathrm{~cm})$. A $2 \%$ benomyl solution was sprinkled over the eggs to inhibit fungal contaminations.

DNA extraction and RAPD-PCR amplification. DNA was isolated from parents and $20 \mathrm{~F}_{1}$ individuals that resulted from the crosses listed. DNA was extracted from the thorax of individual beetles using a modified protocol of Black and DuTeau (1997) $\mathrm{CTAB}$ (hexadecyltrimethylammonium bromide) extraction as described by Clark et al. (2001).

Reagents used for polymerase chain reaction, except primers, were obtained from Applied Biosystems (Foster City, CA). Five samples of the two Diabrotica subspecies, 
randomly selected from the colony, were used for the initial screening of 20 arbitrary primers (Operon Technologies, Inc., Alameda, CA) (Table 4). Optimization of reaction was achieved by following the methods described by Pornkulwat et al. (1998) with the optimized protocol being reported here in. Individual RAPD-PCR reactions were conducted in $25-\mu \mathrm{L}$ volumes (for each primer) with the following reagents: $12.2 \mu \mathrm{L}$ sterile distilled water, $2.5 \mu \mathrm{L} 10 \mathrm{X}$ Stoffel buffer, $3 \mu \mathrm{L}$ of $10 \mathrm{mM}$ dNTPs $(2.5 \mathrm{mM}$ of each dATP, dCTP, dGTP, dTTP), $1 \mu \mathrm{L}$ of the appropriate 10 -mer primer, $1 \mu \mathrm{L}$ of $1 \%$ Nonidet $\mathrm{P}-40$, $0.3 \mu \mathrm{L}$ of AmpliTaq®DNA Polymerase Stoffel fragment (Applied Biosystems, Foster City, CA), $4 \mu \mathrm{L}$ of $25 \mathrm{mM} \mathrm{MgCl}_{2}$ and $1 \mu \mathrm{L}$ of DNA template. For DNA polymerase chain reaction, a negative control that consisted of water was included to check for potential contamination. The polymerase chain reaction was conducted using the following temperature profile: an initial denaturing at $95^{\circ} \mathrm{C}$ for $5 \mathrm{~min}$, then 10 cycles at $94^{\circ} \mathrm{C}$ for $1 \mathrm{~min}, 36^{\circ} \mathrm{C}$ for $30 \mathrm{sec}$, and $72^{\circ} \mathrm{C}$ for $1 \mathrm{~min}$, followed by 30 cycles of $94^{\circ} \mathrm{C}$ for $10 \mathrm{sec}$, $35^{\circ} \mathrm{C}$ for $30 \mathrm{sec}$, and $72^{\circ} \mathrm{C}$ for $30 \mathrm{~s}$; and a final extension step of $72^{\circ} \mathrm{C}$ for $5 \mathrm{~min}$. All RAPD-PCRs were performed using a Perkin-Elmer Gene Amp® System 2400 (Perkin-Elmer, Branchburg, NJ). Upon completion of the PCR reaction, $8 \mu \mathrm{L}$ of the PCR product and $2 \mu \mathrm{L}$ dye (bromophenol) (including a negative control) was loaded on $2 \%$ Ultrapure Agarose Gel (Gibco-BRL, Gaithersburg, MD), DNA molecular size standards ( $1 \mathrm{~kb}$ ladder and 100 ladder $\mathrm{bp}$ ), were added to the outside two wells of each gel, and electrophoresed at $60 \mathrm{~V}$ for $4 \mathrm{~h}$ on a Horizon 20-25 electrophoresis chamber. After electrophoresis, each gel was stained in ethidium bromide $(10 \mathrm{ng} / \mathrm{ml})$ visualized over a UV transilluminator, and scanned into the Advanced Quantifier gel documentation program (Genomic Solutions, Ann Arbor, MI) and, thus, estimates of size relative to known size standards were determined. Primers that generated 6 or more bands with complex banding patterns were eliminated. Of the 20 arbitrary primers screened, only 2 arbitrary primers (OPH 11 and OPH 17 primer sets, Table 4) produced clear, consistent, discrete and reproducible 4 RAPD markers. These were selected for further examination. When the screening process was repeated, the same banding patterns were produced by 2 arbitrary primers. The 2 primers were

Table 1. Color of some adult morphological characters of $D$. undecimpunctata undecimpunctata and $D$. undecimpunctata howardi

\begin{tabular}{|c|c|c|}
\hline & D. u. undecimpunctata & D. u. howardi \\
\hline Antennae & $\begin{array}{l}\text { First three segments tan remaining } \\
\text { nine segments black }\end{array}$ & $\begin{array}{l}\text { First three segments white } \\
\text { remaining nine segments }\end{array}$ \\
\hline \multicolumn{3}{|l|}{ Pronotum } \\
\hline dorsal & Yellow & Yellow \\
\hline ventral & Black & Yellow \\
\hline Abdomen & Black & Yellow \\
\hline \multicolumn{3}{|l|}{ Legs } \\
\hline coxa & Black & Greenish-yellow \\
\hline trochanter & Black & Greenish-yellow \\
\hline femur & Black & $\begin{array}{l}\text { Half greenish-yellow and } \\
\text { half black }\end{array}$ \\
\hline tibia & Black & Black \\
\hline tarsus & Black & Black \\
\hline
\end{tabular}


used for determining body color of the $F_{1}$ progenies of the Diabrotica subspecies and run on the same gel.

Body color analysis. Body color of individuals for each cross was established from RAPD fingerprinting profiles of (OPH 11 and $\mathrm{OPH} 17$ primer sets, Table 4) by comparing shared RAPD markers between $F_{1}$ progeny (20 individuals), and the male parents. Bands of identical molecular weight were considered as the same allele at that locus between individuals. The absence of a band represents the recessive genotype at the locus and also was scored in the analysis of genetic similarity (Black 1993). The proportion of matches, $M$ (the shared presence/ absence of a band) was estimated from: $M=N_{a b} / N_{T}$ where $N_{a b}$ is the total number of matches in individuals $\mathrm{a}$ and b and $N_{T}$ is the total number of bands scored in the study (Black 1993). Individuals are identical (have identical banding patterns) when $M=1$, and are completely dissimilar, share no bands, when $M=0$. Amplified bands were scored directly from digitized images of gels using the Advanced Quantifier program (Genomic Solutions, Ann Arbor, Ml).

Inheritance of body color. Five crosses of the following (i.e., individual crosses between 5 females and 5 males) were made: (1) D. u. undecimpunctata $q \times D . u$. howardi of (2) D. u. howardi $q \times D$. u. undecimpunctata of (Fig. 1). Females were placed with the respective males for $48 \mathrm{~h}$. Each female was then placed in a small oviposition box as described in the insect culture section (Boetel and Fuller 1997), and beetles were fed as described in the insect culture section. The goodness of fit of segregation ratios were measured with chi-square $\left(X^{2}\right)$ analysis of the resulting ratios was compared with a 3:1 Mendelian ratio.

\section{Results}

Body color and morphological characters as markers. Copulation was observed for all crosses. Based on abdomen and leg color patterns, all of the $F_{1}$ progeny had the color of the male parent in all the crosses (Tables 2, 3, Fig. 2).

In crosses between $D$. u. undecimpunctata females and males, the abdominal color of all the $F_{1}$ progeny was black $(n=20)$, whereas in the crosses between spotted cucumber females and spotted cucumber males, the abdominal color of all the progeny was yellow $(n=20)$. However, when the females of $D$. u. undecimpunctata mated with the males of $D$. u. howardi, the abdominal color of all the progeny was yellow. When the females of $D$. $u$. howardi mated with $D$. u. undecimpunctata males, the abdominal color of all the progeny was black $(n=20)$ (Table 3 ). In all the crosses, $F_{1}$ progenies had leg colors identical to their male parents (Table 3).

Initial RAPD primer screening and body color analysis. The two arbitrary primers $\mathrm{OPH}-11$ and $\mathrm{OPH}-17$ (Table 4) that produced clear, consistent, discrete and reproducible RAPD markers were used for determining paternity in the two subspecies of Diabrotica.

Polymerase chain reactions with RAPD primers $\mathrm{OPH}-11$ and $\mathrm{OPH}-17$ yielded a series of repeatable discrete bands that were used to determine the paternity of the $20 \mathrm{~F}_{1}$ progeny from each cross. In all the crosses, the male determined the body color of all the progeny. The bands generated by primers $\mathrm{OPH}-11$ and $\mathrm{OPH}-17$ in all the parents and $F_{1}$ progeny ranged from $150-700$ bp (Tables 5,6 ). Within a cross, parental RAPD profiles matched corresponding progeny profiles (Tables 5,6 ). For example, using primer $\mathrm{OPH}-11$, the presence of $\sim 550$, and $\sim 450$, bp products were used to determine body color of the progeny (Table 5). Similarly, using primer OPH- 


\section{q (black abdomen) $\times \hat{o}$ (yellow abdomen)

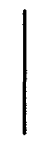

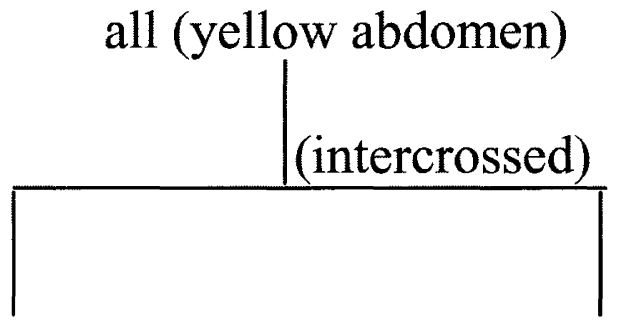

$\mathrm{F}_{1}$

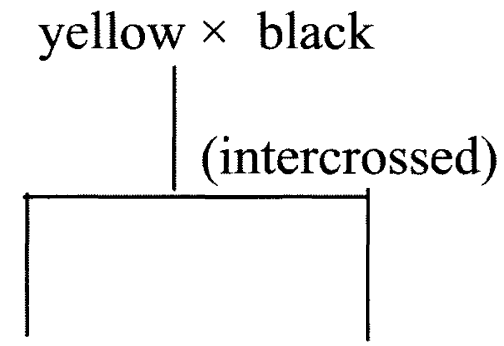

(black) $1 \mathrm{~F}_{2}$

yellow

black

black

$\mathrm{F}_{3}$

Fig. 1. Mating scheme used for studying inheritance of body color in two Diabrotica subspecies. (black $=D$. u. undecimpunctata, yellow $=D$. u. howardi).

17 , presence of $\sim 700$, and -570 , bp products were used for determining body color of the progeny (Table 6 ). Analysis of band matches between fathers and the resultant $F_{1}$ progeny revealed $M=1$ in matches between the male and the $F_{1}$ progeny. This indicated that the male determines the body color of progeny in crosses.

Inheritance of body color. The cross between $D$. $u$. undecimpunctata females and $D . u$. howardi males resulted in the following $F_{1}$ progeny ratio: 75 beetles with the color of selected morphological characters as in spotted cucumber to 0 beetles with color of selected morphological characters as in D. u. undecimpunctata (Table 4). The cross between the spotted cucumber females and western cucumber males resulted in the following $F_{1}$ progeny: 55 beetles with color of selected morphological characters as in $D$. u. undecimpunctata to 0 beetles with color of selected morphological characters as in $D . u$. howardi (Table 4).

$F_{2}$ progeny from the mating of $F_{1}$ beetles that resulted from parental crosses between $D$. $u$. undecimpunctata females and spotted cucumber males segregated into 48 beetles with color of selected morphological characters as in D. U. howardiand 14 beetles with morphological characters as in $D$. $u$. undecimpunctata (Table 7). This 


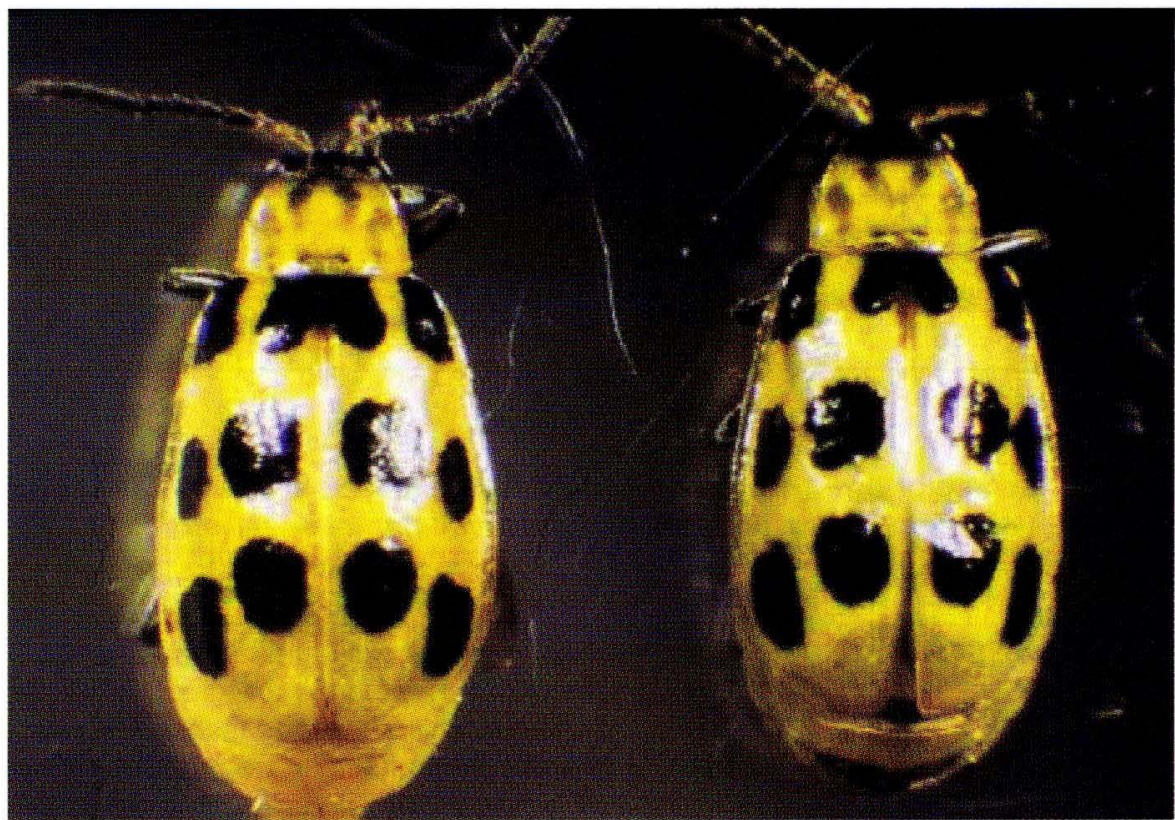

$\mathbf{A}$

B

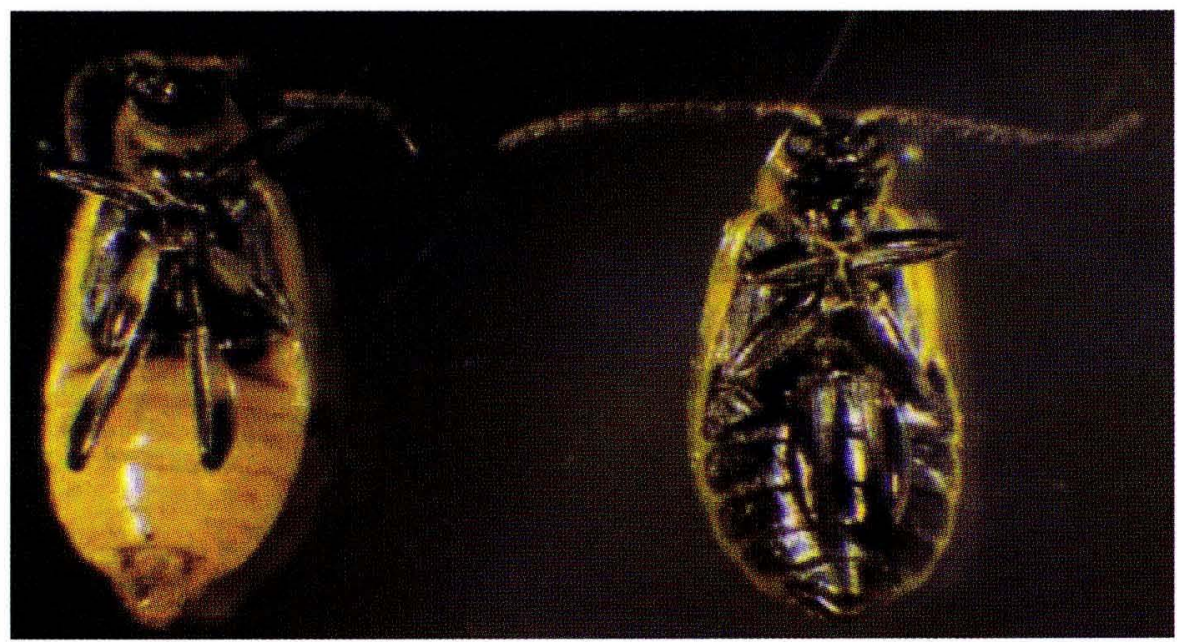

C

D

Fig. 2. (A and B) Adults, D. u. howardi (left), and D. u. undecimpunctata (right), showing the dorsal portion of the body. (C and D) Adults, D. u. howardi (left), and $D$. $u$. undecimpunctata (right), showing the ventral portion of the body (Photo courtesy of Pete L. Clark). 
Table 2. Abdomen color of $\mathbf{F}_{\mathbf{1}}$ progeny resulting from crosses involving Diabrotica undecimpunctata undecimpunctata and Diabrotica undecimpunctata howardi

\begin{tabular}{|c|c|c|}
\hline Crosses & Abdomen color $F_{1}$ progeny & $F_{1}$ designation \\
\hline WSCB $+\times$ WSCB 0 & Black & WSCB \\
\hline SCB $9 \times$ SCB $\sigma$ & Yellow & SCB \\
\hline WSCB $9 \times$ SCB 0 & Yellow & SCB \\
\hline SCB $9 \times$ WSCB ${ }^{\star}$ & Black & WSCB \\
\hline
\end{tabular}

$N=20$ beetles for each cross

Table 3. Leg color of $F_{1}$ progeny resulting from crosses involving Diabrotica undecimpunctata and Diabrotica undecimpunctata howardi

\begin{tabular}{|c|c|}
\hline Crosses & Leg color of $F_{1}$ progeny \\
\hline WSCB $9 \times$ WSCB $\delta$ & Coxa, trochanter, femur, tibia and tarsus are black \\
\hline $\mathrm{SCB}+\times \mathrm{SCB} \sigma \widehat{ }$ & $\begin{array}{l}\text { Coxa, trochanter and half femur are greenish-yellow } \\
\text { while half femur, entire tibia and tarsus are black }\end{array}$ \\
\hline WSCB $9 \times$ SCB ${ }^{*}$ & $\begin{array}{l}\text { Coxa, trochanter and half femur are greenish-yellow } \\
\text { while half femur, entire tibia and tarsus are black }\end{array}$ \\
\hline $\operatorname{SCB} q \times$ WSCB ${ }^{\star}$ & Coxa, trochanter, femur, tibia and tarsus are black \\
\hline
\end{tabular}

$\mathrm{N}=20$ beetles for each cross

Table 4. The 20 arbitrary 10-mer primers used to determine genetic markers for body color of $F_{1}$ progenies from crosses of Diabrotica undecimpunctata undecimpunctata and Diabrotica undecimpunctata howardi

\begin{tabular}{cccc}
\hline \hline Primer & Sequence & Primer & Sequence \\
\hline OPH-01 & GGTCGGAGAA & OPH-11** & CTTCCGCAGT \\
OPH-02 & TCGGACGTGA & OPH-12 & ACGCGCATGT \\
OPH-03 & AGACGTCCAC & OPH-13 & GACGCCACAC \\
OPH-04 & GGAAGTCGCC & OPH-14* & ACCAGGTTGG \\
OPH-05 & ACTCGTCCCC & OPH-15 & AATGGCGCAG \\
OPH-06 & ACGCATCGTG & OPH-16 & TCTCAGCTGG \\
OPH-07 & CTGCATCGTG & OPH-17 & CACTCTCCTC \\
OPH-08 & GAAACACCCC & OPH-18 & GAATCGGCCA \\
OPH-09 & TGTAGCTGGG & OPH-19* & CTGACCAGCC \\
OPH-10 & CCTACGTCAG & OPH-20 & GGGAGACATC \\
\hline
\end{tabular}

* Primers that show clear consistent banding patterns

** Primers that show clear consistent banding patterns that were reproducible when process repeated.

segregation fits the ratio $3: 1\left(X^{2}=0.193\right)$, indicating monogenic dominance of each gene for body color and the other selected morphological characters.

$F_{2}$ progeny from the $F_{1}$ (from parental crosses of spotted cucumber females and D. u. undecimpunctata males) segregated into 37 beetles with the color of selected 
Table 5. The number of and size (bp) of RAPD bands using OPH-11, found in parents and twenty $F_{1}$ progenies crosses between Diabrotica undecimpunctata undecimpunctata and Diabrotica undecimpunctata howardi

\begin{tabular}{|c|c|c|c|}
\hline RAPD marker (bp) ${ }^{1}$ & \multicolumn{2}{|c|}{ Parents } & $F_{1}$ progeny \\
\hline \multicolumn{4}{|c|}{${ }^{\star}$ black $q \times$ black ${ }^{\star}$} \\
\hline 550 & 0 & 550 & 550 \\
\hline 350 & 350 & 0 & 0 \\
\hline 150 & 150 & 150 & 150 \\
\hline \multicolumn{4}{|c|}{ black $+x^{* *}$ yellow $\delta$} \\
\hline 450 & 0 & 450 & 450 \\
\hline 350 & 350 & 0 & 0 \\
\hline 150 & 150 & 150 & 150 \\
\hline \multicolumn{4}{|c|}{ yellow $ᄋ \times$ yellow $\delta$} \\
\hline 450 & 0 & 450 & 450 \\
\hline 400 & 400 & 0 & 0 \\
\hline 150 & 150 & 150 & 150 \\
\hline \multicolumn{4}{|c|}{ yellow $q \times$ black ${ }^{\star}$} \\
\hline 550 & 0 & 550 & 550 \\
\hline 400 & 400 & 0 & 0 \\
\hline 150 & 150 & 150 & 150 \\
\hline
\end{tabular}

1 All bands used in paternity analysis.

${ }^{*}$ black $=D$. u. undecimpunctata

${ }^{\star \star}$ yellow $=D, u$. howardi

morphological characters as in $D . u$. undecimpunctata, and 11 beetles with color of selected morphological characters as in D. u. howardi (Table 5). This segregation fits the ratio of $3: 1\left(X^{2}=0.111\right)$ indicating monogenic dominance of color of morphological characters as in $D$. u. undecimpunctata over the color and selected morphological characters as in $D$. u. howardi (Table 7 ). The $F_{2}$ progeny from the above parental crosses showed inheritance patterns typically expected of a dominant genetic trait.

\section{Discussion}

Results from this study demonstrate that selected morphological characters such as body color can be used as paternal markers in $D$. $u$. undecimpunctata and $D$. $u$. howardi as all subspecific crosses resulted in progeny that had body color patterns that were identical to the male parent. When the $F_{1}$ progeny of the initial subspecific crosses were taken to the $F_{2}$ and $F_{3}$ color patterns in these 2 Diabrotica subspecies fit the Mendelian 3:1 ratio, implying that both yellow and black coloration is controlled by one major gene that is dominant. This was further evidenced by a lack of resulting progeny having an intermediate color pattern in any subsequent generation $\left(F_{1}, F_{2}\right.$ or $F_{3}$ ). However, because the observed 3:1 Mendelian ratio in the $F_{3}$ population was different from the expected theoretical ratio of $4: 1$, we speculate that the inheritance of body color could be more complex as has been observed in other chrysomelid species. Lu and Logan (1994) reported that two loci with epistasis controlled larval body color. They also observed that the male in all the crosses determined the color 
Table 6. The number of and size (bp) of RAPD bands using OPH-17, found in parents and twenty $F_{1}$ progenies in crosses Diabrotica undecimpunctata undecimpunctata and Diabrotica undecimpunctata howardi

\begin{tabular}{|c|c|c|c|}
\hline RAPD marker $(b p)^{1}$ & & Parents & $F_{1}$ Progeny \\
\hline \multicolumn{4}{|c|}{${ }^{*}$ black $q \times$ black $\hat{\jmath}$} \\
\hline 700 & 0 & 700 & 700 \\
\hline 550 & 550 & 0 & 0 \\
\hline 150 & 150 & 150 & 150 \\
\hline \multicolumn{4}{|c|}{ black $q \times{ }^{* \star}$ yellow ${ }^{\star}$} \\
\hline 570 & 0 & 570 & 570 \\
\hline 550 & 550 & 0 & 0 \\
\hline 150 & 150 & 150 & 150 \\
\hline \multicolumn{4}{|c|}{ yellow $q \times$ yellow $\delta$} \\
\hline 570 & 0 & 570 & 570 \\
\hline 450 & 450 & 0 & 0 \\
\hline 160 & 150 & 150 & 150 \\
\hline \multicolumn{4}{|c|}{ yellow $q \times$ black ${ }^{\star}$} \\
\hline 700 & 0 & 700 & 700 \\
\hline 450 & 450 & 0 & 0 \\
\hline 180 & 150 & 150 & 150 \\
\hline
\end{tabular}

Table 7. Segregation ratio of body color in $F_{1}$ and $F_{2}$ progeny in crosses involving adults of Diabrotica undecimpunctata undecimpunctata and Diabrotica undecimpunctata howardi

\begin{tabular}{|c|c|c|c|c|c|c|c|c|}
\hline \multirow{2}{*}{$\frac{\text { Parents crosses }}{q \times \hat{\sigma}}$} & \multicolumn{2}{|c|}{$F_{1}$} & \multicolumn{2}{|c|}{$\mathrm{F}_{2}$ observed } & \multirow{2}{*}{$\frac{F_{2} \text { expected }}{B: Y}$} & \multirow[b]{2}{*}{$X^{2}$} & \multirow[b]{2}{*}{ df } & \multirow[b]{2}{*}{$P^{3}$} \\
\hline & $\mathrm{B}^{1}$ & $\mathrm{Y}^{2}$ & $\mathrm{~B}$ & $\mathrm{Y}$ & & & & \\
\hline black $\times$ yellow & 0 & 75 & 14 & 48 & $(1: 3)$ & 0.193 & 1 & $0.66^{\star}$ \\
\hline yellow $\times$ black & 55 & 0 & 37 & 11 & $(3: 1)$ & 0.111 & 1 & $0.74^{*}$ \\
\hline Parents crosses & \multicolumn{2}{|c|}{$\mathrm{F}_{2}$} & \multicolumn{2}{|c|}{$\mathrm{F}_{3}$ observed } & $F_{3}$ expected & & & \\
\hline$q \times \sigma^{0}$ & $\mathrm{~B}^{1}$ & $Y^{2}$ & B & $\mathrm{Y}$ & $\mathrm{B}: \mathrm{Y}$ & $x^{2}$ & df & $P^{3}$ \\
\hline black $\times$ yellow & 14 & 48 & 11 & 35 & $(1: 3)$ & 0.029 & 1 & $0.86^{*}$ \\
\hline yellow $\times$ black & 37 & 11 & 25 & 7 & $(3: 1)$ & 0.167 & 1 & $0.68^{*}$ \\
\hline
\end{tabular}

${ }^{1}$ B (Black) D. u. undecimpunctata

${ }^{2} \mathrm{Y}$ (Yellow) D. u. howardi

${ }^{3}$ *Cannot reject

of the larvae. These findings support our results that male determines the color of its progeny in these beetles.

Similar results have been observed in other insect species. For example, Boiteau (1988) used body color to document sperm precedence and ultimately paternity in $L$. 
decemlineata, where $\mathrm{F}_{1}$ progeny had similar body color as their second male parent, while Eady (1991) observed similar results for C. maculatus $F$.

Our examination of paternity using RAPD markers confirmed observations that the male determines body color in our subspecies crosses as has been reported in other studies (Hadrys et al. 1993, Hooper and Siva-Jothy 1996). Whereas other molecular methods (AFLP, Microsatellites, etc.) may be more appropriate for large populationbased studies, the RAPD technique proved useful in our study where we examined controlled matings between the $D$. undecimpunctata subspecies. Similar studies on other Diabrotica species, such as economically important $D$. v. virgifera, could provide answers to biological questions such as mate choice, paternity, sperm precedence, and mating frequency.

Answers to these questions could prove important as $D$. $v$. virgifera is targeted for control by $\mathrm{Bt}$ transgenics and maintaining susceptibility to these transgenics is important for management of this technology. Therefore, a similar study using selected $D$. v. virgifera color morphs or populations could be initiated to examine the mating biology in these species where results could provide valuable insights into resistant questions.

In conclusion, we demonstrated that inheritance of color of selected morphological characters is paternally inherited in two subspecies of $D$. undecimpunctata and that this inheritance can be confirmed using molecular techniques such as RAPD. Similar investigations on other species, subspecies or populations may provide important insights into the mating of economically important pests.

\section{Acknowledgments}

The authors are grateful for the cooperation and technical assistance of $\mathrm{J}$. Brown of the Applied Insect Ecology and Pest Management Laboratory and S. Spomer of the Insect Ecology Laboratory, University of Nebraska-Lincoln, and also would like to thank Drs. Robert Wright and Marion Ellis of the Department of Entomology University of Nebraska-Lincoln, and Dr. Bruce Hibbard, of USDA-ARS Plant Genetics Research, University of Missouri Columbia for reviewing this manuscript. This paper is No. 14481, Journal Series, Nebraska Agricultural Division and contribution, Department of Entomology, University of Nebraska-Lincoln.

\section{References Cited}

Achmann, K., G. Heller and J. T. Epplen. 1992. Last -male sperm precedence is the bushcricket Poecillimon veluchianus (Orthoptera: Tettigonoidae) demonstrated by DNA fingerprinting. Mol. Ecol. 1: 47-54.

Black, W. C. 1993. PCR with arbitrary primers: approach with care. Insect Mol. Biol. 2: 1-7.

Black, W. C. and N. W. Du Teau. 1997. RAPD-PCR and SSCP analysis for insect population genetic studies, Pp. 361-373. In Crampton, J. M., C. B. Beard and C. Louis (eds.), Molecular biology of insect disease vectors: a methods manual. Chapman and Hall, London.

Boetel, M. B. and W. Fuller. 1997. Seasonal emergence-time effects on adult longevity, fecundity, and egg viability of northern and western corn rootworms (Coleoptera: Chrysomelidae). Environ. Entomol. 26: 1208-1212.

Boiteau, G. 1988. Bionomics and genetics of a black mutant Colorado potato beetle, Leptinotarsa decemlineata (Coleoptera: Chrysomelidae). Environ. Entomol. 26: 1208-1212.

Branson, T. F., J. J. Jackson and G. R. Sutter. 1988. Improved method for rearing Diabrotica virgifera virgifera (Coleoptera: Chrysomelidae). J. Econ. Entomol. 81: 410-414.

Clark, T. L. L., J. Meinke and J. E. Foster. 2001. Molecular phylogeny of Diabrotica beetles 
(Coleoptera: Chrysomelidae) inferred from analysis of combined mitochondrial and nuclear DNA sequences. Insect Mol. Biol. 10: 303-314.

Cuthbert Jr., F. P., C. S. Creighton and R. B. Cuthbert II. 1968. Mass rearing of banded cucumber beetles, with notes on rearing spotted and striped cucumber beetles. J. Econ. Entomol. 61: 288-292.

Eady, P. E. 1991. Sperm competition in Callosobruchus maculatus (Coleoptera: Bruchidae): a comparison of two methods used to estimate paternity. Ecol. Entomol. 16: 45-53.

Hadrys, H., B. Schier, S. L. Dellaport, R. Dessalle and L. W. Buss. 1993. Determination of paternity in dragonflies by Random Amplified Polymorphic DNA fingerprinting. Mol. Ecol. 2: 79-87.

Hooper, R. E. and M. T. Siva-Jothy. 1996. Last male sperm precedence in a damselfly demonstrated by RAPD profiling. Mol. Ecol. 5: 449-452.

Hoy, M. 1990. DNA amplification by the polymerase chain reaction: Molecular biology made accessible, Pp. 203-244. Insect Molecular Genetics, Academic Press, San Diego, CA.

Huettel, M. D., C. Calkins and A. J. Hill. 1976. Allozyme markers in the study of sperm precedence in the plum curculio, Contrichelus nenuphar. Ann. Entomol. Soc. Am. 69: 465468.

Krysan, J. L. 1986. Introduction biology, distribution, and identification of pest Diabrotica, Pp. 1-23. In Krysan J. K. and T. A. Miller (eds.), Methods for the Study of Pest Diabrotica. Springer-Verlag, NY.

Lu, W. and P. Logan. 1994. Inheritance of larval body color in Leptinotarsa decemlineata (Coleoptera: Chrysomelidae). Ann. Entomol. Soc. Am. 87: 454-459.

Pornkulwat, S., S. R. Skoda, G. D. Thomas and J. E. Foster. 1998. Random amplified polymorphic DNA used to identify genetic variation in ecotypes of the European corn borer (Lepidoptera: Pyralidae). Ann. Entomol. Soc. Am. 91: 719-725.

Smith, C. E. and J. E. Lawrence. 1967. Clarification of the status of the type specimens of Diabroticites (Coleoptera: Chrysomelidae, Galerucinae). Univ. Calif. Publ. Entomol. 45: 174 pp.

Tallamy, D. W. and J. D. Pesek. 1996. Carbon isotopic signatures of elytra interspecific Genetic variation in the gustatory perception of cucurbitacins by diabroticite rootworms (Coleoptera: Chrysomelidae). Environ. Entomol. 26: 1364-1372. 